anaesthetist's armamentarlúm. As the operating surgeon has several methods whlch he may adopt in the radical cure of hernia, $80 \mathrm{I}$ think it is advantageous not to be too stereotyped in our methods of administering an anaesthetic, and to suit the anaesthetic and its method of administration to the case and condition of the patient, for, after all, the personal element is a great factor in anaesthetic work.

Those members of the Association who visited the May0s' Hospital in Rochester. when at the annual meeting last year, have seen the method adopted, it is caid, in every case; but I must confess. I myself would not apply it In every case, becanse I do not think it suitable to all the different types of patlents one meets with here in England. Their babits may be different; elther it may be that the climatic conditions in this country are different, and so the rate of evaporation of ether is not the eame, or the ether itself may have a specific gravity unlike that used in America; whlch cause is at work I am not prepared to say.

I have long been an advocate for the open method of ether administration, using solely an Allis inhaler; but it Is not my purpose in this short note to enter into the pros and cons of the open or closed method; I wish to describe a method whlch appeals to me on account of the simplicity of the apparatus which we all possess, since it consists merely of a Skinner's inhaler, a plece of gauze or Gamgee tissue, and a bottle with a ganze wlck.

The Bottle and Wick.-An ordinary $6 \mathrm{oz}$. or $8 \mathrm{oz}$, mediclne bottle answers the purpose well; a slit is made in the side of the cork to allow of the passage of a strip of gauze, which ought to reach to the bottom of the bottle, 8 , if this is the case, we are better able to regulate the flow.

The Inhaler. -The pattern known as Schimmelbusch's is perhaps as suitable as any ; over it is placed a piece of stockinette bandage, which appears to answer more advantggeously than flannel, and may easily and instantaneously be changed; lastly, we require a strip of gauze rolled Into a ring, with a diameter sufficlently large to encircle the patient's nose and mouth; some use a piece of Gamgee tiasue, with a hole to admit the nose and mouth, which answers the purpose equally well.

The Method of Administration.-First place the Skinner's mask over the patient's face as in using it for chloroform; allow a few drops of ether to trickle on the mask, and when the patient has become used to the smell, put the ring pad of gauze round the nose and mouth, resting the Skinner's mask upon it, and increase the rate of flow of the ether by tilting the bottle; it is necessary to keep this flow constant, either at a diminished or increased rate, according to the requirements of the case.

In conclusion, I may say I have used this method in children and adults : with children, for example, in circumcision operations it appears to be universally satiefactory, and with adults it answers well in thin anaemic females or extremely exhausted subjects, but in the plethoric man or fat woman it requires much patience and much ether to produce an ansesthetic state.

There are one or two polnts which ought to be observed during administration; it is well to keep the patient's head Inclined, so that if mucus be secreted in excess it may not gravitate into the trachea and set up bronchial affections; should the inhaler inadvertently get too soaked, it also prevents any drops of ether getting into the farices, and so setting up violent coughing; these are untowards incidents which may happen during first efforts, and it is just as well to bear them in mind ; although $I$ trust eventualities, which may happen in any method of producing anaesthesia, will not prevent the adoption of this method should occasion arise.

IN a recent article on insurance companies, the Daily Telegraph says that of all those who work for these companies, few render such valuable service as do the medical examiners, but little is heard abjut them. The success of any company largely depends upon the skill with which the medical men connected with it do their work. There are some pitfalls in their path, but happily for insurance companies the medical profession as a whole possesses a very sensitive conscience, and the reports made are as accurate and as fair as possible. In everything to do with insurance work doctors as a whole have a very fine record. The tornado of scandal in connexion with insurance companies which ruined so many reputations in America not long ago, left those of medical men not only unsmirched but even unassailed.

\section{AN OPEN CONTINUOUS DROP METHOD OF} ADMINISTERING ETHER.

BY ALEXANDER BROWNLEE, F.R.C.S.E., HONORARY ANAESTHETIST, CARDIFF INHIRMARY.

With Remarks by

J. LynN THOMAs, C.B., F.R.O.S.

Ether, as 18 well known, bas been given in various open and semi-open methods for many years. For the past twelve months I have been giving ether by an open continuous drop method. Last January I read a short paper before the Cardiff Division of the British Medical Assoclation on the subject, and the present paper was in the courge of preparation when Dr. Gardner's article appeared, in the Journal of November 23rd. Mirs Alice Magaw, an American lady anaesthetist, records 14,000 cases of ether administered by the drop method "without a death directly due to the anaesthetic," and I am indebted to Mr. Lynn Thomas who saw ber practising it, for my Initial instruction in it.

The apparatus is simple and Inexpens ive. The mask is slightly larger than the ordinary Schimmelbusch's and fits the face more closely. It is covered with about 16 layers of sterilized gauze. The drop bottle is an ordinary $6 \mathrm{oz}$. bottle, with a plain cork in which two grooves are cut. One groove is larger than the other, and a strand of wool passes through it, the smaller groove allowing air to pass into the bottle and the ether coming out.by capillary action. By means of this slmple arrangement, a steady drop is obtained. Although I have trled many of the ordinary drop bottles, I have not been able to get the eame regular steady drop with one of them. I find it best to have $\mathbf{Z}$ drop bottles, the grooves in the corks being. cat so that a large drop is got from one and a smaller drop from the other. It is essential to bear in mind that ether should never be poured on the mask. If this be done, the result generally is that some ether gets into the patient's mouth, and there is an attack of coughing. In some of my early csses, in which I fell into this mistake, a rigid eondition of the abdominal wall was the result, and I had to dlspense with ether and "push" the administration of chloroform to overcome 1 .

The patient havlng been put on the table, the mask is placed on the face, and the administration commenced by slowly dropping ether on the mask until the patient becomes somewhat accustomed to the smell. The ether is then dropped more rapidly, and the mask surrounded, if necessary, by a towel until the patient's face is completely hidden. As the patient goes "under" the towel may be removed. The administration can then be continued with the smaller drop bottle. I am bound to say, however, that I find considerable difficulty in inducing anaesthesia in strong or alcohollc men by this means, and in the case of such subjects $I$ begin with a mixture of chloroform and ether (CHCl $_{3} 1$ part, ether 3 parts), get the patient fairly well under with this, and then continue with ether alone. Once ansesthesia is established there is no difficulty in maintaining it. In the cases of children, women, and in men in any way emaciated or weak, complete anaesthesia can be induced by this method with ether alone in from three to ten minutes.

Up to date I have conducted 257 administrations, and the results have been, I consider, highly satisfactory. The ages and conditions of the patients operated on have varled within wide limits. Thus my youngest patient was 2 years old; my eldest 73 . The cases have included all clases of patients-strong, healthy men, alcoholics, neurotic women, patients emaciated by malignant disease and other debilitating conditions, and serious accident cases. The shortest administration lasted seven minates, the longest three hours. In the great majority of the cases the condition of the patient was very satisfactory. There is not the anxiety assoclated with the administration of chloroform, while many of the objectlonable f atures of ether administration with the Clover or other closed apparatus are eliminated. There is less secretion of mucus than when the latter is employed, and the respiratory excnrsions of the abdominal wall are not 80 vigorous-a point not without importance to the surgeon in operations requiring fine manipulation. The breathing is invariably of a regular snoring type, the puplls 
moderately contracted, and reacting very sluggishly, or not at all, to light, and the colour 18 good. The last point is one which presents a great contrast to the condition almost always prevailing when a closed apparatus is used - that of cyanosis.

As regards after-effects, post-anaesthetic sickness is Jessened, and there is assuredly less shock than when chloroform is used. In the course of my administrations oy this method I lave only had one really bad case.

The patient was a boy aged 16, with advanced tuberculosis of the knee-joint ; exclsion of the knee was performed, and the operation lasted an hour and a half. Ansesthesla was induced and maintained throughout with other by the drop method. For forty-five minutes the patient's condition was good, and presented the ordinary signs of ether administered in this way, but at the end of that time it changed, the breathing becoming shallow and the patient pale and cold. The pulse, however, remained fairly good. The anaesthetic was withdrawn for fifteen minutes without any sign of consclousness drawn for fifteen minutes without any sign of consciousness returning, but he then developed a clonic condition of the muscles of the leg, and the operator desired more ansesthetic
given. This was done, but as he soon showed signs of extreme collapse, it was withdrawn entirely and finally twenty minutes before the operation was finished. Half an hour after being returned to bed there was no improvement in his condition, and the ward sister remarked that he seemed to be very deeply under the anaesthetic. An hour after the termination of the operation the resident medical officer ordered a brandyand-coffee enema, but it was not retained. However, after sleeping for three hours, he gradually came round, and sleeping for three hours, he gradually

In contrast to this, I have had many cases where prolonged operations, Involving considerable shock, have been extremely well borne.

A man of 46, suffering from carcinoma of the stomacb, bore an extensive operation very well, although the altimate result was unfavourable. In this case about three-fourths of the stomaoh was removed, together with a part of the duodenum, the hepatic flexure, transverse colon, and splenic flexure. The operation lasted two hours and twenty-five minutes, and the patient left the table with a pulse of 84 . He did well for four days, but on the filth day he developed symptoms of pneumonla and died within twenty-four hours.

Another case was one of prostatectomy in a man of 71. This patient was in very bad condition, ss he was slightly under the influence of morphine and was suffering from toxsemis. The breath had a urinous odour. The operation lasted one hour, but he stood it well and made a complete recovery.

The longest administration-three hours-was for the removal of gall stones. The operation was well borne, and the patient made a perfect recovery.

One case, where death was possibly attributable to the ansesthetio, falls to be recorded. This was a case of goître in a girl of 19. Anaesthesia was induced with the $\mathrm{C} \mathrm{E}$ mixture and maintained with ether. The whole administration lasted seventy minutes, and there was no cause for any anxlety throughout. However, on the evening of the operation the temperature shot ap, physical signs of pneumonia developed, temperature shot up, physical signs of pneumoni
and she died o. the fourth day after the operation.

In summing up I may say I do not claim that this method of administering ether is perfect. It has, like other anaesthetics and methods of administerlng them, advantages and disadvantages, but the former in $\mathrm{my}$ opinion far outweigh the latter.

The only disadvantages I have experienced are (1) the difficulty in inducing anaesthesis in strong or alcoholic men in a reasonable time with ether alone, (2) the quantity of ether used, which is undoubtedly greater than when a closed apparatus is used.

The advantages are numerons (1) it is cleanly in the surgicel sense. The mask can be boiled and sterillzed ganze used. Contrast this with ether administered with a closed apparatus, where the patient rebreathes his own explred vitiated air from an apparatus whlch cannot be sterilized and is in fact with difficulty. kept clean. (2) The cyanosis violent respiratory movements, excessive secretion of mucus with the consequent gurgling, frothing, coughing, etc. are greatly diminished and in many cases entirely abolished. (3) There is less shock than when chloroform is used. (4) Many of the unpleasant after-effects commonly associated with ether administered from a closed apparatus, are done away with.

RhMarks by Mr. J. Ifyna Thomas,

The first time I saw the method used was at the hospital of the brothers Mayo, of Rochester, Minnesota ; subsequently I saw it employed in Dr. Ochner's practice. Having seen the method used over a hundred times, I. was favourably impressed with it, and it has been 6 adopted almost entirely in my practice during the last twelve months. Its advantages over glving ether in Clover's inhaler are :

1. There is less capillary haemorrhage during operations.

2. There is less sickness after operations.

3. The surgeon is not bothered with the bag, which may or may not be sterlle, when operating about the chest, neck, face, or head.

4. The whole mask is easily sterllized.

5. There is much less anxiety to the surgeon when it is glven by an anaesthetist of little experience.

In one of the cases referred to by Mr. Brownlee the peration lasted two and a half hours. After removing three-fourths of the stomash and a large portion of the duodenum, together with the whole of the transverse colon with its mesentery and glands, I had to occlude the ends of the duodenum of the ascending colon, and the descending colon, and had to perform a gastrojejunostomy under difficulties, because the stump of the stomach would not be brought out to the surface. I had also to perform an ileo-sigmoidostomy, and although the operation was very extensive the shock could not have been less. The patient recovered and was quite cheerful within six hours.

So far I have seen no case in which there has been any anxiety from the administration of the anaesthetic, either during the operation or subsequently. I consider it a method well worth trying, as it is simple and clean, but a little more expensive on account of the larger quantity of ether nsed.

\section{MALIGNANT ENDOCARDITIS LASTING OVER} SIX MONTHS WITHOUT BRUIT.

BY ROBERT CAPES, M.R.C.S.ENG., L.R.C.P.LOND،, DENMARK HILI.

THF interesting point in the following case is that, although The illness and the pprexis lasted seven months, at no time was a bruit ever heard; though the patient was aeen by five medical men, all of whom were looking out for signs of heart disease. The rapid wasting at the end, with the enlargement of the liver and spleen, and loss of consciousness, made the theory of growth seem likely, though the continued rise of temperature for so many months was against it.

Hence although the petechlae, the pyrexla, and the slightly increased heart.rate all pointed to a possible fangating endocarditis, a positive diagnosis was not arrived at. Even towards the end, as the liver became quite as much enlarged in proportion as the spleen, the diagnosis still remained doubtiul. Cases not infrequently occur in which for a long time there is no bruit, or only a very doubtfal one; but it is very exceptional for a case of such prolonged daration to remain without a brult throughout.

History.

J. M., a male, aged 64, was first seen on February 26th, 1906. He gave the following hlstory : Had been confined to bed for ten days or a fortnight with influenza, followed by pain and swelling of the calf of the left leg, and subsequently by.
similar condition; though not so severe, in the right leg. His slmilar condition; though not so severe, in the right leg. His condition corresponded with the history; his temperature was normal in the mornings, but occasionally in the evenings reached $99.4^{\circ} \mathrm{F}$. or $99.8^{\circ} \mathrm{F}$, ; the heart sounds were normal and the breath sounds also, with the exception of slight crepitation at the base of the left lung. He was kept in bed until the pet abont with si elestic stocking on o went to Hatings for ohange of air.

On his return from Hastings, on March 20th, he said he was not feeling much better, hls ohief conplaint belng that he not feeling much better, his ohief conplaint being that he easily got tired. His temperature was nsually over 99 $\mathrm{F}$. in the morning

On April lith he went to Matlock, and from there to Liverpool, and back to town about April 25th. He still said he did not feel any better, but resumed business.

On May 3 r I found he was still going up to business, but Hlways returned home tired out, and with the evening rise, of temperature.

On May. 10th he was seen by Dr. Goodhart, who reported no physical signs of disease, condition of organs normal, and advised \& further period of rest to be followed br changs of
air. Dr. Goodhert in a subsequent letter wrote : "I remember 